\title{
1 Predictive Modeling of Pseudomonas syringae Virulence on Bean using Gradient
}

\section{Boosted Decision Trees}

3

4 Renan N.D. Almeida ${ }^{1}$, Michael Greenberg ${ }^{1}$, Cedoljub Bundalovic-Torma ${ }^{1}$, Alexandre Martel ${ }^{1}$,

5 Pauline W. Wang ${ }^{1,2}$, Maggie Middleton ${ }^{1}$, Syama Chatterton ${ }^{3}$, Darrell Desveaux ${ }^{1}$, and David S.

6 Guttman ${ }^{1,2, *}$

7

$8{ }^{1}$ Department of Cell \& Systems Biology, University of Toronto, 25 Willcocks St., Toronto,

9 Ontario, Canada

10

$11{ }^{2}$ Centre for the Analysis of Genome Evolution \& Function, University of Toronto, Toronto,

12 Ontario, Canada

13

$14{ }^{3}$ Agriculture and Agri-Food Canada, Lethbridge Research and Development Centre, Lethbridge,

15 Alberta, Canada

16

17 *To whom correspondence should be addressed. Email: david.guttman@utoronto.ca

19 Running title: Predicting P. syringae virulence on bean using a machine learning approach

21 Keywords: Pseudomonas syringae, Phaseolus vulgaris, bean, machine learning, random forest, 22 gradient boosted decision trees, host specificity, virulence, 


\section{ABSTRACT}

Pseudomonas syringae is a genetically diverse bacterial species complex responsible for numerous agronomically important crop diseases. Individual isolates of $P$. syringae are typically assigned pathovar names based on their host of isolation and the associated disease symptoms, and these pathovar designations are often assumed to reflect host specificity. Unfortunately, this assumption has rarely been rigorously tested, which poses a challenge when trying to identify genetic factors associated with host specificity. Here we develop a rapid seed infection assays to measure the virulence of 121 diverse $P$. syringae isolates on common bean (Phaseolus vulgaris). This collection includes $P$. syringae phylogroup 2 bean isolates (pathovar syringae) that cause bacterial spot disease and $P$. syringae phylogroup 3 bean isolates (pathovar phaseolicola) that cause the much more serious halo blight disease. We find that phylogroup 2 strains generally show lower levels of host specificity on bean, with the average level of virulence for all strains in this phylogroup (irrespective of host of isolation) being higher than the average level for all other $P$. syringae strains. We then use gradient boosted decision trees to model the $P$. syringae virulence weights using whole genome kmers, type III secreted effector kmers, and the presence / absence of type III effectors and phytotoxins. Our machine learning model performed best using whole genome data, and we were able to predict bean virulence with high accuracy (mean absolute error as low as 0.05 ). Finally, we functionally validated the model by predicting virulence for 16 strains and found that $15(94 \%)$ of the strains had virulence levels within the bounds of estimated predictions given the calculated RMSE values $( \pm 0.20)$. This study further illustrates that $P$. syringae phylogroup 2 strains may have evolved a different lifestyle than other $P$. syringae strains and demonstrates the power of machine learning for predicting host specific adaptation. 


\section{INTRODUCTION}

Pseudomonas syringae is a genetically diverse Gammaproteobacterial species complex

\section{3}

responsible for numerous agronomically important crop diseases (1-4). Strains in the $P$. syringae species complex are frequently categorized into pathovars depending on pathogenic characteristics such as host of isolation and disease symptoms $(5,6)$. Strains have also been subdivided into phylogenetic groups (i.e., phylogroups) based on multilocus sequence typing or genomic analysis (1, 7-10). Currently, there are 13 recognized phylogroups (7), of which seven have been termed primary phylogroups based on their genetic relatedness and the near universal presence of the canonical $P$. syringae type III secretion system (discussed below) (1, 9).

Phylogenetic analyses of $P$. syringae isolates suggests that adaptation to specific hosts has evolved multiple times in the evolutionary history of the species complex. For example, cherry and plum pathogens are found in clades distributed in phylogroups 1,2 , and $3(11,12)$, hazelnut pathogens are distributed among two distinct clades in phylogroups 1 and 2 (13), while pathogens of common bean (including snap, green, kidney, and French bean) are found in phylogroups 2 and 3 (9). Common bean pathogens from $P$. syringae phylogroup 3 are generally classified as pathovar phaseolicola and are responsible for halo blight disease, which is characterized by large necrotic lessons surrounded by a chlorotic zone (halo) of yellow tissue (14-16). Bean pathogens of phylogroup 2 are generally classified as pathovar syringae and are responsible for bacterial spot disease, which is characterized by brown leaf spots $(17,18)$. While halo blight can cause very serious crop losses, bacterial spot disease is generally of only minor agronomic concern. The phylogroup 3 phaseolicola bean isolates show a high degree of phylogenetic clustering, with most strains sharing a relatively recent common ancestor that is closely related to a compact sister clade of soybean pathogens. In contrast, phylogroup 2 
syringae bean isolates show very little phylogenetic clustering and are frequently more closely related to a non-bean isolates than another bean isolates (9).

Assuming that host specificity is a heritable trait, the exploitation of a common host by divergent lineages of strains can be explained by a number of different mechanisms, including: 1) evolution via shared, vertically transmitted host specificity factors; 2) convergent evolution via unrelated genetic mechanisms; or 3) convergent evolution via the horizontal acquisition of host specificity factors from divergent lineages. Another layer of complexity is that host specificity could come about either through the gain of genetic factors that promotes growth on a new host, or alternatively, by the loss of a factor that otherwise limits growth (e.g., by inducing a host immune response). In fact, the most thorough study of host convergence in $P$. syringae suggests that isolates can make use of multiple mechanisms simultaneously. For example, diverse lineages of cherry pathogens use multiple mechanisms to cause disease and have exchanged and lost key genes that contribute to successful infections multiple times $(11,12)$.

One of the most important and dynamic classes of $P$. syringae virulence and host specificity factors are type III secreted effectors (T3SEs). T3SE are proteins secreted through the type III secretion system and translocated directly into the eukaryotic host cell where they can directly interfere with host immunity or disrupt cellular homeostasis to promote the disease process. There are 70 distinct families of $P$. syringae T3SEs, and most strains carry a suite of T3SEs consisting of 12 to 50 T3SEs, with an average of 30 (19). Plants have responded to T3SEs by evolving immune receptors and complexes that trigger an effector-triggered immune (ETI) response when they detect the presence or activity of a T3SE $(20,21)$. Consequently, the outcome of any particular host-microbe interaction depends to a large degree on the specific T3SE profile of the pathogen, and the complement of immune receptors carried by the host. The

101 strong selective pressures imposed by the host-microbe arms race results in very dynamic 
102 evolution of T3SEs in general, with very frequent horizontal transmission, acquisition, and loss

$103(9,19,22)$.

104

105 While nearly every strain in phylogroups 2 and 3 carries a substantial suite of T3SEs, the suites

106 vary in size, with phylogroup 3 strains carrying an average of $\sim 27$ T3SEs vs. $\sim 19$ for phylogroup

1072 strains (19). Phylogroup 2 strains are also known to carry more phytotoxins, which contribute

108 to virulence and niche competition via a variety of mechanisms such as membrane disruption

109 and mimicking of hormones $(3,9,23)$. In general, phylogroup 2 strains are believed to show

110 lower levels of host specificity and better ability to survive on leaf surfaces (i.e., epiphytic

111 growth) $(1-3,24)$.

112

113 The application of statistical genetic and machine learning approaches to genomic data has

114 greatly increased our power to identify genes underlying traits of interest, such as host

115 specificity (25). Statistical genetic approaches such as genome-wide association studies

116 (GWAS) are well developed for studying human traits and have more recently gained traction in

117 the study of bacterial traits as statistical and phylogenetic methods have been developed for

118 dealing with the shared evolutionary history of segregating genetic variants (i.e., population

119 structure) (26-31). While GWAS approaches have great power for finding genotype-phenotype

120 associations, they generally measure associations on a locus-by-locus basis, and therefore can

121 miss more complex interactions among loci that impact traits. An alternative approach for

122 predicting genotype-phenotype associations is to use machine learning, which generally

123 describes a large range of statistical approaches that create models derived from a dataset

124 consisting of features (e.g., genetic variants) linked to a trait or outcome (e.g., host specificity).

125 These models can be used to predict outcomes from new samples or to identify the feature(s)

126 that carry the most importance in the model. Machine learning approaches are better at 
127 identifying suites of interacting genetic variants than GWAS, but they are more limited in their

128 ability to deal with complex evolutionary relationships among these variants.

129

130 Here, we implemented a rapid, high-throughput method for screening a proxy of virulence for $P$.

131 syringae isolates on common bean. We use this screen to assess virulence of 121 strains from

132 nine phylogroups on bean, and then impute the virulence for an additional set isolates based on

133 their core genome relationship to the screened strains. While the majority of bean pathogens

134 come from phylogroups 2 and 3, we find that phylogroup 3 pathogens display a much stronger

135 degree of host specificity in comparison to phylogroup 2 pathogens. Finally, we develop a

136 random forest regression model using genomic kmers and virulence factors as features to

137 predict the virulence of $P$. syringae isolates on bean.

\section{MATERIALS AND METHODS}

142 Strain collection. Three hundred and thirty-four Pseudomonas syringae strains were used in

143 this study (Table S1). Forty-six P. syringae isolates were collected from bean fields

144 approximately $80 \mathrm{~km}$ East of Lethbridge, Alberta, Canada, during the summer of 2012. Bean

145 leaves with symptoms of bacterial diseases were collected from new growth during the

146 vegetative growth stage. The remaining 288 isolates were previously published (9) and include

14749 P. syringae type and pathotype strains (1, 32). A type strain is the isolate to which the

148 scientific name of that organism is formally attached under the rules of prokaryote

149 nomenclature, while a pathotype strain is similar but with the additional requirement that it has

150 the pathogenic characteristics of its pathovar (i.e., a pathogen of a particular host) (5). Out of

151 the 334, 318 strains were used for comparative analyses and model training, while 16 were

152 used for model functional validation. A subset of 267 non-clonal representative strains 
153 (discussed below) were selected for the predictive modeling to avoid clonal bias. A further

154 subset of 121 isolates, including the type and pathotype strains, were selected for virulence

155 assays.

156

157 Sequencing and quality control. DNA was extracted using the Gentra Puregene Yeast and

158 Bacteria kit (Qiagen, Hilden, Germany). Illumina libraries with 300-400 bp inserts were

159 generated using the Illumina Nextera XT kit according to the manufacturer's protocol (Illumina,

160 CA, USA). Samples were multiplexed with the Illumina Nextera XT Index kit containing 96

161 indices. Samples were sequenced on the Illumina NextSeq 500 Mid Output v2 (300 cycle) kit

162 with 150 base PE reads. All sequencing was performed at the University of Toronto's Centre for

163 the Analysis of Genome Evolution and Function (CAGEF). Raw read quality was assessed with

164 FastQC. Trimmomatic was used to remove adapters and trim raw sequencing reads based on a

165 sliding window approach ( window size $=4$, required quality $=5$ ).

166

167 De novo assembly. Paired-end reads were de novo assembled using the CLC Genomics

168 Assembly Tool (CLC Genomics Workbench). Contigs shorter than $1 \mathrm{~kb}$ were removed from the

169 assemblies. Low coverage contigs with matches to non-Pseudomonas genera and no matches

170 to the Pseudomonas genus that had a depth of coverage less than one standard deviation from

171 the average assembly coverage were deemed contaminants and, therefore, removed from the

172 final draft.

173

174 Pangenome analysis, gene prediction, annotation, and orthologous clustering. Gene

175 prediction and annotation for all assemblies were performed with Prokka (33). Prokka annotates

176 proteins by searching for sequence similarity in the UniProtKB (34) database and HMM libraries

177 (35). Additionally, all predicted genes were aligned against a custom T3SE database for the

178 identification of potential T3SEs (19). Orthologs were inferred with PIRATE (36), which clusters 
179 genes into orthologous groups by performing all-vs-all comparisons followed by MCL clustering

180 given a certain percent identify threshold. Genes present in at least $95 \%$ of the genomes were

181 classified as core. Core protein families were individually aligned with MUSCLE (37) and later

182 concatenated into a single protein alignment. We used FastTree2 (38) to infer the phylogenetic

183 relationships of all 318 isolates.

184

185 Identification of non-clonal representative strains. We reduced the impact of phylogenetic

186 bias in our predictive modeling by selecting only one representative strain from each clonal

187 group (i.e., very closely related strains recently derived from a common ancestor). We identified clonal groups by calculating the pairwise core genome evolutionary distance and the Jaccard similarity for T3SE profiles. We found the minimum pairwise core-genome evolutionary distance for isolates with identical T3SE profiles to be 0.001 average substitutions per site. We therefore pooled the 318 isolates if they had a core genome evolutionary distance of less than 0.001 , resulting in 209 clusters. We further supplemented these clusters by adding back any strain that had a T3SE profile Jaccard similarity value less than 0.8 , resulting in 267 non-clonal clusters. A

194 single representative was selected out of each of these non-clonal clusters for downstream analyses. One exception was made to the strain selection process in order to balance our experimental design, which was skewed due to the fact that the vast majority of phylogroup 3

197 bean isolates (i.e., pathovar phaseolicola) fall into one clonal group. Initially, our selection

198 criteria resulted in only six phylogroup 3 bean isolates compared to 16 phylogroup 2 bean

199 isolates (i.e., pathovar syringae). We therefore added an additional seven phaseolicola strains

200 to the screened set to better balance the number of bean isolates in phylogroups 2 and 3 .

201 Evolutionary distances and Jaccard similarity scores were inferred with MEGA7 (39) and R 202 version $4.0 .5(40)$. 
204 Seed infection virulence assay. P. syringae strains were grown overnight at $30^{\circ} \mathrm{C}$ in King's B

205 media, re-suspended in $10 \mathrm{mM} \mathrm{MgSO}_{4}$ and diluted to an $\mathrm{OD}_{600}$ of 0.001. P. vulgaris var.

206 Canadian red seeds were soaked for 24 hours in the bacterial suspension, planted in Sunshine

207 Mix 1 soil with regular watering and grown for 14 days. Plant fresh weight and germination

208 frequencies were measured and normalized to a control plant treated with $10 \mathrm{mM} \mathrm{MgSO}_{4}$ sown

209 on each flat.

210

211 Syringe infiltration virulence assays. $P$. syringae strains were grown overnight on appropriate

212 antibiotics, re-suspended in $10 \mathrm{mM} \mathrm{MgSO}_{4}$ and diluted to $\mathrm{OD}_{600}$ of 0.001 . Two- to three-week-

213 old Phaseolus vulgaris var. Canadian red plants were syringe infiltrated and bacterial growth

214 assays were carried out by harvesting eight leaf disks $\left(1 \mathrm{~cm}^{2}\right)$ from each plant (two per each

215 primary leaf) three days after infiltration. Disks were homogenized using a bead-beater in $200 \mu \mathrm{l}$

216 sterile $10 \mathrm{mM} \mathrm{MgSO}_{4}$, serially diluted in 96-well plates, and $5 \mu \mathrm{l}$ from each dilution was spot

217 plated on KB supplemented with rifampicin for positive and negative control strains, and

218 rifampicin and kanamycin for strains harboring constructs. Plates were incubated for at least 24

219 hours at $30^{\circ} \mathrm{C}$ and the resulting colony counts were used to calculate the number of CFUs per

$220 \mathrm{~cm}^{2}$ in the leaf apoplast.

221

222 Predictive modeling of $\boldsymbol{P}$. syringae virulence on bean. We used an implementation of

223 gradient boosted decision trees to model the effect of $P$. syringae isolates on plant weights

224 using: 1) whole genome kmers, 2) T3SE kmers, and 3) a presence / absence matrix of T3SEs

225 and phytotoxins. We split sequences into 31-mers with fsm-lite and generated a binary matrix

226 for kmers with identical distribution patterns using custom python scripts. Next, we used the

227 Scikit-learn and the XGBoost python libraries (41) to generate a regression model for the

228 prediction of normalized plant weights using all three datasets as input features. Given the

229 relatively small size of our dataset, we used a cross-validation (CV) procedure to assess the 
230 performance of our model on 50 independent splits. For each time, we randomly split the data

231 into training (80\%) and testing (20\%) sets while maintaining the same plant weight distributions

232 on both sets. Hyper parameters were fine-tuned using Scikit-learn's RandomizedSearchCV

233 module and regression models were generated with XGBoost's XGBRFRegressor module.

\section{RESULTS}

Virulence screen development. We developed a high-throughput seed infection assay to measure the virulence of $P$. syringae isolates on common bean. We used seed infection based on the understanding that many bean infections are caused by contaminated seeds $(42,43)$

$240(14,44)$. These infections can reduce overall plant health, which is reflected in plant fresh weight. For the screen, we soaked bean seeds ( $P$. vulgaris var. Canadian Red) in a $P$. syringae suspension ( $5 \times 10^{5}$ cells $\left./ \mathrm{ml}\right)$ for 24 hours prior to planting. Plant fresh weight was then determined after 14 days. We first assessed if plant weight was correlated with in planta bacterial load by comparing our seed infection assay to the traditional syringe infiltration virulence assay using 24 P. syringae isolates from 9 out of the 13 phylogroups (Fig. 1). Wellestablished bean pathogens such as $P$. syringae pv. phaseolicola 1448A (Pph1448A) $(14,16)$ and $P$. syringae pv. syringae B728a (PsyB728a) $(17,45)$ showed the highest levels of bacterial growth and lowest plant weights, while the other isolates from phylogroups 1-7, 11, and 13 showed a range of values. On the whole there was a significant negative association between bacterial growth and plant weight $\left(R^{2}=0.63, P+5.0 e-6\right)$, supporting the use of seed infection and

251 plant fresh weight to assess bacterial virulence.

253 To determine the power of this assay, we performed initial seed infection trials with six $P$.

254 syringae isolates and 50 or more replicate plants. We used a rarefaction analysis of normalized 255 plant weights to determine the number of replicate plants required to distinguish pathogens from 
256 non-pathogens with $>95 \%$ confidence (Tukey-HSD test) and found that the test power

257 plateaued at $\sim 20$ replicates per treatment (Fig. S1). Therefore, we performed future seed

258 infection assays using 30 replicate plants per treatment.

260 Virulence screen. We screened 121 non-clonal representative $P$. syringae isolates from nine

261 phylogroups to assess the virulence potential as measured by reduced plant fresh weight in 14-

262 day old bean plants after seed infection. The screened strains resulted a highly skewed

263 distribution of normalized fresh weights (i.e., virulence), with a mean of 0.78 , median of 0.94 ,

264 and standard deviation of 0.30 (Fig. 2). An examination of the 30 strains in the first quartile

265 revealed normalized fresh weights between 0.00 and 0.61 , with $56.7 \%$ (17 strains) being bean

266 isolates. These 17 strains represent $58.6 \%$ of all 29 bean isolates in screened.

268 Significant differences in virulence, as measured by normalized fresh weight, were observed

269 when comparing the strain collection stratified by host of isolation and phylogroup (Table 1). The

27029 bean isolates had an average virulence (normalized fresh weight) of 0.59 compared to 0.85

271 for the 92 non-bean isolates ( $p=4.2 e-5,2$-tailed, heteroscedastic T-test). All of the bean isolates

272 are found in phylogroups 2 and 3, so we compared the virulence of bean isolates to non-bean

273 isolates within these two phylogroups individually and found no significant difference for

274 phylogroup 2 ( $p=0.128,2$-tailed, heteroscedastic T-test) but a strong difference for phylogroup 3

275 ( $p=8.9 e-4,2$-tailed heteroscedastic T-test). Additionally, there were no significant differences

276 between phylogroup 2 and phylogroup 3 bean isolates $(p=0.460)$. We then looked for

277 differences in virulence between strains from different phylogroups irrespective of their host of

278 isolation (only comparing phylogroups with at least six tested strains, using 2-tailed,

279 heteroscedastic T-tests, Bonferroni corrected for seven total tests), and found that strains in

280 phylogroup 2 were significantly more virulent on bean than strains from phylogroups 1,3 , and 4

$281(p=1.33 e-07,0.012$, and 0.029 respectively $)$, but not relative to phylogroup 6 . In contrast, 
282 strains from phylogroup 3 were only significantly more virulent on bean than strains from

283 phylogroup 1 ( $p=0.006)$. No other significant pairwise phylogroup comparisons were observed.

284 Interestingly, when we asked if non-bean phylogroup 2 isolates showed higher virulence on

285 bean than non-bean isolates from all other phylogroups, we observed a significant difference

$286(p=2.87 e-4)$ indicating that while bean isolates specifically show greater virulence on bean,

287 phylogroup 2 isolates in general also show greater virulence on bean. This pattern was actually

288 reversed in phylogroup 3 where non-bean isolates had significantly lower virulence than non-

289 bean isolates from all other phylogroups $(p=4.52 e-3)$.

290

291 Virulence and germination inhibition. We then assessed whether the virulence of a strain

292 also influenced the germination frequency of bean seeds. Pathogenic microbes are known to

293 interfere with the seed germination $(42,43,46)$ both through the direct action of phytotoxins (23)

294 and the indirect action of immune activation. In fact, seedling growth inhibition is a well-

295 established assay for immune activation in Arabidopsis thaliana (47). In general, the frequency

296 distribution for bean germination inhibition was much less skewed than the frequency

297 distribution for virulence, with mean $=60.1 \%$, media $=63.3 \%$, and standard deviation $=24.3 \%$

298 (Fig 2, Table 1). The average germination frequency for all bean isolates was $45.9 \%$ compared

299 to $64.6 \%$ for non-bean isolates ( $p=4.92 e-4$, 2-tailed, heteroscedastic T-test). When stratifying

300 the bean isolates by phylogroup, we found no significant difference in germination frequency

301 between phylogroup 2 bean and non-bean isolates $(p=0.076)$, while there was for phylogroup 3

$302(p=0.002)$, and we did observe a significant difference between germination frequency for

303 phylogroup 2 bean isolates and phylogroup 3 bean isolates $(p=0.014)$. Similar to what was

304 found for the virulence assays, phylogroup 2 strains were significantly different from strains from

305 phylogroups 1,3 , and $4(p=0.010,6.23 e-5,8.53 e-11$ respectively 2 -tailed, heteroscedastic T-

306 test, Bonferroni corrected), while phylogroup three strain were also significantly different from

307 phylogroup $4(p=2.23 e-4)$. Also similar to the virulence results, non-bean phylogroup 2 isolates 
308 result in lower germination rates than all other non-bean isolates $(p=9.60 e-5)$, while non-bean

309 phylogroup 3 strains had a higher germination rate than non-bean isolates from all other

310 phylogroups $(p=0.004)$, although this pattern disappears when non-bean phylogroup 2 strains

311 were removed from the analysis.

312

313 Finally, we measured the association between virulence (i.e., normalized fresh weight) and

314 germination frequency and found a strong association between the two metrics for the full

315 dataset $\left(R^{2}=0.46, p=2.2 e-16\right)$. Stratifying by phylogroup and bean isolates showed a strong

316 association for phylogroup 2 bean isolates (linear regression; $F=28.91, \mathrm{df}=13, \mathrm{p}=0.0001, \mathrm{R}^{2}=$

317 0.68), but no significant association for phylogroup 3 bean isolates $\left(R^{2}=0.62, p=0.06\right)($ Fig 3$)$.

318

319 Predictive modelling of $\boldsymbol{P}$. syringae virulence on bean. We used a gradient boosted decision

320 tree regression model to predict the virulence of $P$. syringae isolates on beans. The model used

321 one of three input feature classes: 1) genomic kmers; 2) T3SE kmers; or 3) presence / absence

322 of T3SEs and phytotoxins. T3SEs and phytotoxins are well-know virulence factors, with the

323 former often strongly associated with host specificity. Plant weight 14 days after seed infection

324 was used as a continuous outcome. The goal of this model was to assess the power of machine

325 learning to predict disease outcomes based on genome sequences and to predict the host

326 specificity of new isolates based on their genome sequence.

327

328 We used two nested collections of strains to generate the model. The first collection included

329 the 114 of the isolates directly screened for virulence, which included 50 phylogroup 2 strains

330 and 42 phylogroup 3 strains. This collection is slightly smaller than the full screened set since it

331 does not include the additional phylogroup 3 bean isolates added to balance the experimental

332 design (q.v., materials and methods). The second collection was an expanded strain set in

333 which we imputed virulence values based on genomic similarity. The imputation process 
334 identified strains in our collection that had a core genome evolutionary distance of less than

3350.001 and a T3SE Jaccard similarity of greater than 0.8 compared to one of the screened

336 strains. Any strains meeting these criteria were assigned the same virulence as the

337 corresponding screen strain. This imputation process almost tripled the size of our sample set,

338 resulting in an expanded collection of 318 strain, which included 67 phylogroup 2 strains and

339142 phylogroup 3 strains. We also tested phylogroup 2 and phylogroup 3 strains separately

340 since bean isolates from these phylogroups interact with their host very differently.

341

342 Our analysis revealed a significant linear relationship between sample size and the overall

343 performance of the models (Fig. 5, MAE linear regression $F=5.89, \mathrm{df}=10, \mathrm{p}=0.03, \mathrm{R}^{2}=0.3$ ).

344 Hence, the data sets with the least number of samples consistently showed the poorest

345 performance regardless of the input data (e.g., phylogroup 2 and the screened collection).

346 Furthermore, our models achieved the highest predictive power when looking exclusively at

347 isolates from PG3, which may be explained by the strong clonality patterns displayed by bean

348 pathogens from this phylogroup. Perhaps not surprisingly, models built using the greatest

349 diversity, with respect to number of strains (i.e., the expanded strain collection) and number of

350 genetic feature (i.e., whole genome kmers) showed the highest predictive power, with the best

351 model having a mean absolute error (MAE) of 0.06 .

352

353 Model functional validation. We evaluate the power of our gradient boosted decision tree

354 regression model on unseen strains by using the kmer profiles of $P$. syringae isolates not

355 previously examined to predict virulence, and comparing these predictions to actual virulence

356 measures obtained through the seed infection virulence assay. Importantly, none of the strains

357 in the functional validation set were clonal related to any screened strain - they did not share a

358 core genome evolutionary distance of $>0.001$ and a T3SE Jaccard similarity of $<0.8$ with any

359 screened strain. When comparing actual to predicted virulence on the 16 strains in the 
360 functional validation set, we found that 15 (94\%) strains had virulence levels within the bounds

361 of estimated predictions given the calculated RMSE values $( \pm 0.20)$ (Fig. 5$)$.

362

\section{DISCUSSION}

364

365 This work addressed the question of whether host of isolation is a reliable predictor of host

366 specific virulence, and conversely, can we use whole genome sequences to predict the host

367 specific virulence potential of individual strains. Pseudomonas syringae host specificity has

368 been studied in one form or another for many years. Some of the earliest molecular plant

369 immunity work was done in P. syringae with the cloning of the first "avirulence" gene (i.e., an

370 ETI-eliciting T3SE) in 1984 (48). Since those early studies, current technologies and

371 methodologies now enable the genome sequencing and functional characterization of hundreds

372 of strains $(9,24,49)$. Despite this outstanding progress, we still have very limited ability to

373 predict the virulence potential of individual strains, even when full genome sequences are

374 available. The host of isolation is an extremely widely used surrogate for host specificity, and to

375 a large extent the basis for the pathovar nomenclature system. Despite the importance of this

376 assumption, it has rarely been systematically studied, and often fails when put to the test (24,

377 49).

378

379 Our first aim was to determine if infection of bean seeds by $P$. syringae recapitulated virulence

380 responses seen in more standard syringe inoculation virulence assays of bacteria into leaves.

381 We found a negative association between normalized plant fresh weight after seed infection and

382 in planta bacterial growth after syringe infiltration into leaf tissue, showing that the alternative

383 infection protocol works, and suggesting that virulence can systemically disrupt growth and

384 development. This finding is consistent with published and anecdotal reports that infected seed

385 stocks are a significance source of bean disease $(42,43,50,51)$. In general, we found that 
386 bean isolates reduced mean plant fresh weight by $30.2 \%$ and median weight by $46.2 \%$

387 compared to non-bean isolates. While the phylogroup 2 leaf spot bean pathogens had a

388 normalized mean fresh weight of $0.56 \pm 0.293$ (stddev) compared to $0.64 \pm 0.246$ for the

389 phylogroup 3 halo blight bean pathogens, this difference was not significantly different. A similar

390 pattern was found when we examined seed germination frequencies, where bean isolates

391 reduced the average germination frequency by $28.9 \%$ and median frequency by $22.0 \%$

392 compared to non-bean isolates. But in this case, the $38.8 \%$ mean germination frequency of

393 phylogroup 2 bean pathogens was significantly lower than the $57.0 \%$ mean germination

394 frequency of the phylogroup 3 bean pathogens $(p=0.014)$.

395

396 Phylogroup 2 strains in general showed lower levels of host specificity on bean. Neither our

397 fresh weight virulence measure nor the germination rates were significantly different between

398 the bean and non-bean isolates of phylogroup 2. This comparison was quite different for

399 phylogroup 3 strains, where bean isolates showed significantly higher virulence and lower

400 germination frequency compared to non-bean isolates from the same phylogroup. These

401 findings are consistent with other studies that have found lower levels of host specificity among

402 phylogroup 2 strains $(24,49)$ and lends support to the hypothesis that phylogroup 2 strains may

403 rely as much or more on toxin than T3SEs than other $P$. syringae strains.

404

405 While many genome-wide association studies have successfully identified strong genotype to

406 phenotype linkages to date, we were unable to identify any loci significantly associated with

407 bean isolation (data not shown). Consequently, we shifted our focus to machine learning

408 approaches as they can not only unravel genomic signatures associated with continuous

409 phenotypes, but also predict the virulence potential of previously unseen isolates given their

410 genome sequences. Regardless of phylogroup affiliation, our model was able to predict the

411 virulence of individual $P$. syringae isolates with low error margins, based solely on whole 
412 genome data. However, the fact that models trained on virulence factors alone could predict

413 virulence with considerable accuracy supports the notion that T3SEs and phytotoxins play

414 crucial roles in host adaptation processes. Nonetheless, the higher predictive power of models

415 trained with whole genome kmers suggests that factors other than virulence-associated genes

416 also play important roles on disease development and adaptation to beans.

417

418 Sample size is one of the most important contributors to accurate model generation in machine

419 learning. Simple models trained with large data sets can learn to distinguish label categories

420 with much stronger accuracy than complex models trained with small datasets. Our results also

421 found a correlation between sample size and model accuracy, with the screened strain

422 collection providing a MAE of 0.153 while the larger imputed strain collection increased model

423 performance to a MAE of 0.065 . We find much poorer model performance for phylogroup 2

424 strains than phylogroup 3 strains. While this may partly reflect the differences in sample size

425 between these two groups, it also likely reflects the underlying biology. The majority of bean

426 isolates in phylogroup 3 are phylogenetically clustered, while there is little clustering of bean

427 isolates in phylogroup 2. Consequently, the model may perform better on phylogroup 3 since it

428 is essentially predicting phylogenetic structure. Another contributing factor is likely the finding

429 discussed above, namely, host specificity appears to be weaker in phylogroup 2. If phylogroup 2

430 strains are more generalists than specialists, then the host specificity signal would be weaker

431 and any model trying to find this signal would perform more poorly. 


\section{REFERENCES}

435

436 1. Baltrus DA, McCann HC, Guttman DS. 2017. Evolution, genomics and epidemiology of

437 Pseudomonas syringae: Challenges in Bacterial Molecular Plant Pathology. Mol Plant

$438 \quad$ Pathol 18:152-168.

439 2. Morris CE, Monteil CL, Berge O. 2013. The life history of Pseudomonas syringae: linking $440 \quad$ agriculture to earth system processes. Annu Rev Phytopathol 51:85-104.

441 3. Xin XF, Kvitko B, He SY. 2018. Pseudomonas syringae: what it takes to be a pathogen. $442 \quad$ Nat Rev Microbiol 16:316-328.

443 4. Morris CE, Sands DC, Vinatzer BA, Glaux C, Guilbaud C, Buffiere A, Yan S, Dominguez

444 H, Thompson BM. 2008. The life history of the plant pathogen Pseudomonas syringae is $445 \quad$ linked to the water cycle. ISME J 2:321-34.

446 5. Bull CT, De Boer SH, Denny TP, Firrao G, Fischer-Le Saux M, Saddler GS, Scortichini M, Stead DE, Takikawa Y. 2008. Demystifying the nomenclature of bacterial plant pathogens. J Plant Pathol 90:403-417.

6. Dye DW, Bradbury JF, Goto M, Hayward AC, Lelliott RA, Schroth MN. 1980. International standards for naming pathovars of phytopathogenic bacteria and a list of pathovar names and pathotype strains. Review of Plant Pathology 59:153-168. 2014. A user's guide to a data base of the diversity of Pseudomonas syringae and its application to classifying strains in this phylogenetic complex. PLoS One 9:e105547.

8. Sarkar SF, Guttman DS. 2004. Evolution of the core genome of Pseudomonas syringae, a highly clonal, endemic plant pathogen. Appl Environ Microbiol 70:1999-2012.

457 9. Dillon MM, Thakur S, Almeida RND, Wang PW, Weir BS, Guttman DS. 2019. Recombination of ecologically and evolutionarily significant loci maintains genetic cohesion in the Pseudomonas syringae species complex. Genome Biol 20:3. 
460 10. Hwang MS, Morgan RL, Sarkar SF, Wang PW, Guttman DS. 2005. Phylogenetic characterization of virulence and resistance phenotypes of Pseudomonas syringae. Appl Environ Microbiol 71:5182-91.

463 11. Hulin MT, Armitage AD, Vicente JG, Holub EB, Baxter L, Bates HJ, Mansfield JW, Jackson RW, Harrison RJ. 2018. Comparative genomics of Pseudomonas syringae reveals convergent gene gain and loss associated with specialization onto cherry

12. Hulin MT, Mansfield JW, Brain P, Xu X, Jackson RW, Harrison RJ. 2018. Characterization of the pathogenicity of strains of Pseudomonas syringae towards cherry and plum. Plant Pathol 67:1177-1193.

13. O'Brien HE, Thakur S, Gong Y, Fung P, Zhang J, Yuan L, Wang PW, Yong C, Scortichini M, Guttman DS. 2012. Extensive remodeling of the Pseudomonas syringae pv. avellanae type III secretome associated with two independent host shifts onto hazelnut. BMC Microbiol 12:141.

14. Arnold DL, Lovell HC, Jackson RW, Mansfield JW. 2011. Pseudomonas syringae pv. phaseolicola: from 'has bean' to supermodel. Mol Plant Pathol 12:617-27.

15. Tsiamis G, Mansfield JW, Hockenhull R, Jackson RW, Sesma A, Athanassopoulos E, Bennett MA, Stevens C, Vivian A, Taylor JD, Murillo J. 2000. Cultivar-specific avirulence and virulence functions assigned to avrPphF in Pseudomonas syringae pv. phaseolicola, the cause of bean halo-blight disease. EMBO J 19:3204-14.

16. Joardar V, Lindeberg M, Jackson RW, Selengut J, Dodson R, Brinkac LM, Daugherty SC, Deboy R, Durkin AS, Giglio MG, Madupu R, Nelson WC, Rosovitz MJ, Sullivan S, 
Pseudomonas syringae pv. phaseolicola 1448A reveals divergence among pathovars in genes involved in virulence and transposition. J Bacteriol 187:6488-98.

17. Feil H, Feil WS, Chain P, Larimer F, DiBartolo G, Copeland A, Lykidis A, Trong S, Nolan

18. Marco ML, Legac J, Lindow SE. 2005. Pseudomonas syringae genes induced during colonization of leaf surfaces. Environ Microbiol 7:1379-1391.

19. Dillon MM, Almeida RND, Laflamme B, Martel A, Weir BS, Desveaux D, Guttman DS. 2019. Molecular evolution of Pseudomonas syringae type III secreted effector proteins. Front Plant Sci 10:418.

20. Buttner D. 2016. Behind the lines-actions of bacterial type III effector proteins in plant cells. FEMS Microbiol Rev 40:894-937.

21. Khan M, Seto D, Subramaniam R, Desveaux D. 2018. Oh, the places they'll go! A survey of phytopathogen effectors and their host targets. Plant J 93:651-663.

22. Martel A, Ruiz-Bedoya T, Breit-McNally C, Laflamme B, Desveaux D, Guttman DS.

508 24. Morris CE, Moury B. 2019. Revisiting the concept of host range of plant pathogens. 
510 25. Allen JP, Snitkin E, Pincus NB, Hauser AR. 2021. Forest and Trees: Exploring Bacterial $511 \quad$ Virulence with Genome-wide Association Studies and Machine Learning. Trends

$512 \quad$ Microbiol doi:10.1016/j.tim.2020.12.002.

513 26. Chen PE, Shapiro BJ. 2015. The advent of genome-wide association studies for $514 \quad$ bacteria. Curr Opin Microbiol 25:17-24.

515 27. Falush D. 2016. Bacterial genomics: Microbial GWAS coming of age. Nat Microbiol $516 \quad 1: 16059$.

517 28. Falush D, Bowden R. 2006. Genome-wide association mapping in bacteria? Trends $518 \quad$ Microbiol 14:353-5.

519 29. Power RA, Parkhill J, de Oliveira T. 2017. Microbial genome-wide association studies: lessons from human GWAS. Nat Rev Genet 18:41-50.

521 30. Sheppard SK, Didelot X, Meric G, Torralbo A, Jolley KA, Kelly DJ, Bentley SD, Maiden MC, Parkhill J, Falush D. 2013. Genome-wide association study identifies vitamin B5 biosynthesis as a host specificity factor in Campylobacter. Proc Natl Acad Sci U S A $110: 11923-7$.

31. Earle SG, Wu CH, Charlesworth J, Stoesser N, Gordon NC, Walker TM, Spencer CC, Iqbal Z, Clifton DA, Hopkins KL, Woodford N, Smith EG, Ismail N, Llewelyn MJ, Peto TE,

530 32. Thakur S, Weir BS, Guttman DS. 2016. Phytopathogen Genome Announcement: draft 531 genome sequences of 62 Pseudomonas syringae type and pathotype strains. Mol Plant $532 \quad$ Microbe Interact 29:243-6.

533 33. Seemann T. 2014. Prokka: rapid prokaryotic genome annotation. Bioinformatics $30: 2068-9$ 
535 34. Apweiler R, Bairoch A, Wu CH, Barker WC, Boeckmann B, Ferro S, Gasteiger E, Huang

536 H, Lopez R, Magrane M, Martin MJ, Natale DA, O'Donovan C, Redaschi N, Yeh LS.

537 2004. UniProt: the Universal Protein knowledgebase. Nucleic Acids Res 32:D115-9.

538 35. Mistry J, Finn RD, Eddy SR, Bateman A, Punta M. 2013. Challenges in homology

539 search: HMMER3 and convergent evolution of coiled-coil regions. Nucleic Acids Res

$540 \quad 41: e 121$

541 36. Bayliss SC, Thorpe HA, Coyle NM, Sheppard SK, Feil EJ. 2019. PIRATE: A fast and

542 scalable pangenomics toolbox for clustering diverged orthologues in bacteria.

$543 \quad$ Gigascience 8.

544 37. Edgar RC. 2004. MUSCLE: a multiple sequence alignment method with reduced time $545 \quad$ and space complexity. BMC Bioinformatics 5:113.

546 38. Price MN, Dehal PS, Arkin AP. 2010. FastTree 2--approximately maximum-likelihood

547 trees for large alignments. PLoS One 5:e9490.

548 39. Kumar S, Stecher G, Li M, Knyaz C, Tamura K. 2018. MEGA X: Molecular Evolutionary

549 Genetics Analysis across Computing Platforms. Mol Biol Evol 35:1547-1549.

550 40. R Development Core Team. 2020. R: A language and environment for statistical

551 computing, R Foundation for Statistical Computing, Vienna, Austria. https://www.R-

552 project.org/.

553 41. Chen T, Guestrin C. 2016. XGBoost: A Scalable Tree Boosting System, Proceedings of 554 the 22nd ACM SIGKDD International Conference on Knowledge Discovery and Data 555 Mining doi:10.1145/2939672.2939785. ACM, San Francisco, California, USA.

556 42. Darrasse A, Bureau C, Samson R, Morris CE, Jacques M-A. 2007. Contamination of 557 bean seeds by Xanthomonas axonopodis pv. phaseoli associated with low bacterial 558 densities in the phyllosphere under field and greenhouse conditions. Eur J Plant Pathol $559 \quad 119: 203-215$. 
560 43. Eyster HC. 1940. The cause of decreased germination of bean seeds soaked in water. $561 \quad$ Am J Bot 27:652-659.

562 44. Hirano SS, Demars SJ, Morris CE. 1981. Survival, establishment, and dispersal of 563 Pseudomonas syringae on snap beans (Phaseolus vulgaris L). Phytopathology 71:881564881.

565 45. Willis DK, Hrabak EM, Rich JJ, Barta TM, Lindow SE, Panopoulos NJ. 1990. Isolation 566 and characterization of a Pseudomonas syringae pathovar syringae mutant deficient In

46. Chahtane H, Nogueira Füller T, Allard PM, Marcourt L, Ferreira Queiroz E, Shanmugabalaji V, Falquet J, Wolfender JL, Lopez-Molina L. 2018. The plant pathogen Pseudomonas aeruginosa triggers a DELLA-dependent seed germination arrest in Arabidopsis. Elife 7.

47. Bredow M, Sementchoukova I, Siegel K, Monaghan J. 2019. Pattern-Triggered doi:10.3791/59437.

48. Staskawicz BJ, Dahlbeck D, Keen NT. 1984. Cloned avirulence gene of Pseudomonas syringae pv. glycinea determines race-specific incompatibility on Glycine max (L.) Merr. Proc Natl Acad Sci U S A 81:6024-8.

49. Morris CE, Lamichhane JR, Nikolić I, Stanković S, Moury B. 2019. The overlapping continuum of host range among strains in the Pseudomonas syringae complex.

581 50. Shade A, Jacques MA, Barret M. 2017. Ecological patterns of seed microbiome diversity, transmission, and assembly. Curr Opin Microbiol 37:15-22.

583 51. Upper CD, Hirano SS, Dodd KK, Clayton MK. 2003. Factors that Affect Spread of Pseudomonas syringae in the Phyllosphere. Phytopathol 93:1082-92. 


\section{TABLES}

587

588

Table 1. Virulence and Germination Assay Summary

\begin{tabular}{|c|c|c|c|c|c|c|c|}
\hline \multirow[b]{2}{*}{ Group ${ }^{1}$} & \multirow{2}{*}{$\begin{array}{c}\mathrm{N} \\
\text { Strains }\end{array}$} & \multicolumn{3}{|c|}{ Virulence $^{2}$} & \multicolumn{3}{|c|}{ Germination Frequency (\%) } \\
\hline & & Mean & Median & Stdv & Mean & Median & Stdv \\
\hline All Strains & 121 & 0.789 & 0.913 & 0.271 & 60.10 & 63.33 & 24.31 \\
\hline PG1 & 8 & 0.972 & 0.995 & 0.043 & 72.99 & 79.17 & 15.71 \\
\hline PG2 & 50 & 0.658 & 0.748 & 0.320 & 46.74 & 53.33 & 26.41 \\
\hline PG3 & 42 & 0.841 & 0.964 & 0.218 & 68.15 & 67.50 & 16.53 \\
\hline PG4 & 6 & 0.924 & 1.000 & 0.147 & 83.61 & 82.50 & 4.52 \\
\hline PG5 & 3 & 0.966 & 1.000 & 0.059 & 73.33 & 78.33 & 10.14 \\
\hline PG6 & 3 & 1.000 & 1.000 & 0.000 & 80.56 & 81.67 & 3.47 \\
\hline PG7 & 2 & 0.956 & 0.956 & 0.062 & 85.00 & 85.00 & 7.07 \\
\hline PG11 & 6 & 0.851 & 0.867 & 0.151 & 43.89 & 50.00 & 20.75 \\
\hline PG13 & 1 & 1.000 & 1.000 & NA & 91.67 & 91.67 & NA \\
\hline All Bean Isolates & 29 & 0.594 & 0.516 & 0.271 & 45.89 & 53.33 & 23.52 \\
\hline All Non-Bean & 92 & 0.850 & 0.960 & 0.244 & 64.58 & 68.33 & 23.05 \\
\hline PG2 Bean & 16 & 0.560 & 0.478 & 0.293 & 36.84 & 32.22 & 26.42 \\
\hline PG2 Non-Bean & 34 & 0.704 & 0.841 & 0.327 & 51.41 & 56.67 & 25.47 \\
\hline PG3 Bean & 13 & 0.635 & 0.606 & 0.246 & 57.02 & 58.89 & 13.21 \\
\hline PG3 Non-Bean & 29 & 0.933 & 1.000 & 0.122 & 73.14 & 73.33 & 15.56 \\
\hline
\end{tabular}

${ }^{1} \mathrm{PG}=$ phylogroup

589

2 Normalized fresh weight 2 weeks after seed infection 
Table 2. Machine Learning Model Performance

\begin{tabular}{lclcc}
\hline Group & Samples & Dataset & MAE & RMSE \\
\hline PG3 & 142 & Whole genome kmers & 0.049 & 0.107 \\
PG3 & 142 & Toxin and T3SE binary matrix & 0.054 & 0.101 \\
Imputed & 318 & Whole genome kmers & 0.067 & 0.140 \\
PG3 & 142 & T3SE kmers & 0.085 & 0.126 \\
Imputed & 318 & Toxin and T3SE binary matrix & 0.092 & 0.153 \\
Imputed & 318 & T3SE kmers & 0.096 & 0.177 \\
PG2 & 66 & T3SE kmers & 0.154 & 0.233 \\
Screened & 114 & Whole genome kmers & 0.155 & 0.204 \\
Screened & 114 & T3SE kmers & 0.159 & 0.213 \\
Screened & 114 & Toxin and T3SE binary matrix & 0.163 & 0.201 \\
PG2 & 66 & Whole genome kmers & 0.169 & 0.242 \\
PG2 & 66 & Toxin and T3SE binary matrix & 0.202 & 0.262 \\
\hline
\end{tabular}




\section{FIGURE LEGENDS}

594

595 Figure 1: Bacterial growth is inversely correlated with plant weight. Bacterial density in

596 syringe infiltrated bean leaves as a function of normalized median weight of seed infected

597 plants. There is a strong negative correlation between bacterial density and plant weight across

598 isolates in the $P$. syringae species complex (linear regression; $F=36.95, \mathrm{df}=21, p=4.95 \mathrm{e}-06$,

$\left.599 R^{2}=0.62\right)$.

600

601 Figure 2: Frequency distribution virulence and germination assays. Distributions of data

602 from the 121 strains screened for virulence (plant fresh weight) and germination by the seed

603 infection assay.

604

605

Figure 3: Normalized median plant fresh weights of seed infected bean plants. $(A)$

606 Boxplots show virulence (normalized plant fresh weight) of $121 P$. syringae strains after seed

607 infection on bean. The boxplots are color-coded by the phylogroup of each strain, and asterisks

608 above the boxplots denote bean isolates. Plants infected with bean isolates tend to have higher

609 virulence (i.e., lower plant fresh weight) than plants infected with strains isolated from other

610 hosts. (B) Germination frequency of seed infected plants. (C) Core genome phylogeny of $318 P$.

611 syringae isolates. Leaf colors represent phylogroup affiliation. Metadata row 1 shows isolation

612 source; metadata row 2 shows normalized median weight of screened isolates, and metadata

613 row 3 shows normalized median weight for the expanded strain collection based on

614 phylogenetic imputation.

615

616 Figure 4: Correlation between germination frequency and virulence of seed infected bean

617 plants. (A) Germination frequency vs virulence (i.e., normalized fresh weight) stratified by 
618 phylogroup (PG) 2 and phylogroup 3 bean isolates. A strong correlation is found between

619 germination frequency and virulence of bean strains from phylogroup 2 (linear regression; $F=$

$\left.62028.91, \mathrm{df}=13, p=0.00012, \mathrm{r}^{2}=0.66\right)$. (B) Germination frequency vs. virulence stratified by

621 phylogroup (PG) irrespective of host.

622

623 Figure 5: Performance of supervised machine learning models on virulence predictions

624 with genome data. Models trained with the screed collection (yellow), imputed expanded

625 collection (blue), imputed expanded phylogroup (PG) 2 set (orange), and imputed expanded

626 phylogroup 3 set (green). Diamonds, circles, and triangles represent models trained with a

627 phytotoxin and T3SE binary matrix, T3SE kmers, and whole genome kmers, respectively. (A)

628 Mean Absolute Error (MAE) as a function of number of samples across 50 cross-validation

629 splits. Increasing the number of samples seen by the model significantly increases model

630 performance (linear regression; $F=5.89, \mathrm{df}=10, p=0.03, \mathrm{r}^{2}=0.37$ ). (B) Root Mean Square

631 Error (RMSE) as a function of number of samples across 50 cross-validation splits. Models

632 trained on whole genome kmers with a higher number of samples consistently outperform other 633 models.

634

635 Figure 6: Correlation between predicted and observed weights of plants infected with

636 isolates previously unseen by the model. (A) Predicted virulence as a function of observed

637 virulence on seed infected bean plants. Color coding indicates phylogroups (PG). Dashed line

638 indicates 1:1 relationship. (B) Virulence for each isolate tested ordered by predicted virulence

639 and colored by phylogroup. The solid line represents virulence predictions for each isolate. The

640 grey box represents the error margins for the predictions based on the MAE and RMSE values

641 for the model.

642

643 


\section{SUPPLEMENTARY MATERIAL}

645

646 Figure S1: Sample size selection via a simulated experimental setup. Bean plants were

647 seed infected with $6 P$. syringae isolates with a high number of replicates $(>50)$. Plant weights

648 were randomly selected according to various replicate sizes (8-32). Our ability to distinguish

649 pathogens from non-pathogens using Tukey-HSD tests plateaus at 20 replicates per treatment.

650

651 Figure S2: MAE and RMSE across 50 cross-validation splits. Model performance in terms of

652 Mean Absolute Error and Root Mean Square Error. Plant weight distributions were kept the

653 same across splits.

654

655 Table S1: List of $P$. syringae isolates used in this study.

656 
bioRxiv preprint doi: https://doi.org/10.1101/2021.05.27.445966; this version posted May 28, 2021. The copyright holder for this preprint (which was not certified by peer review) is the author/funder. All rights reserved. No reuse allowed without permission.

\section{Fig 1}

658

659

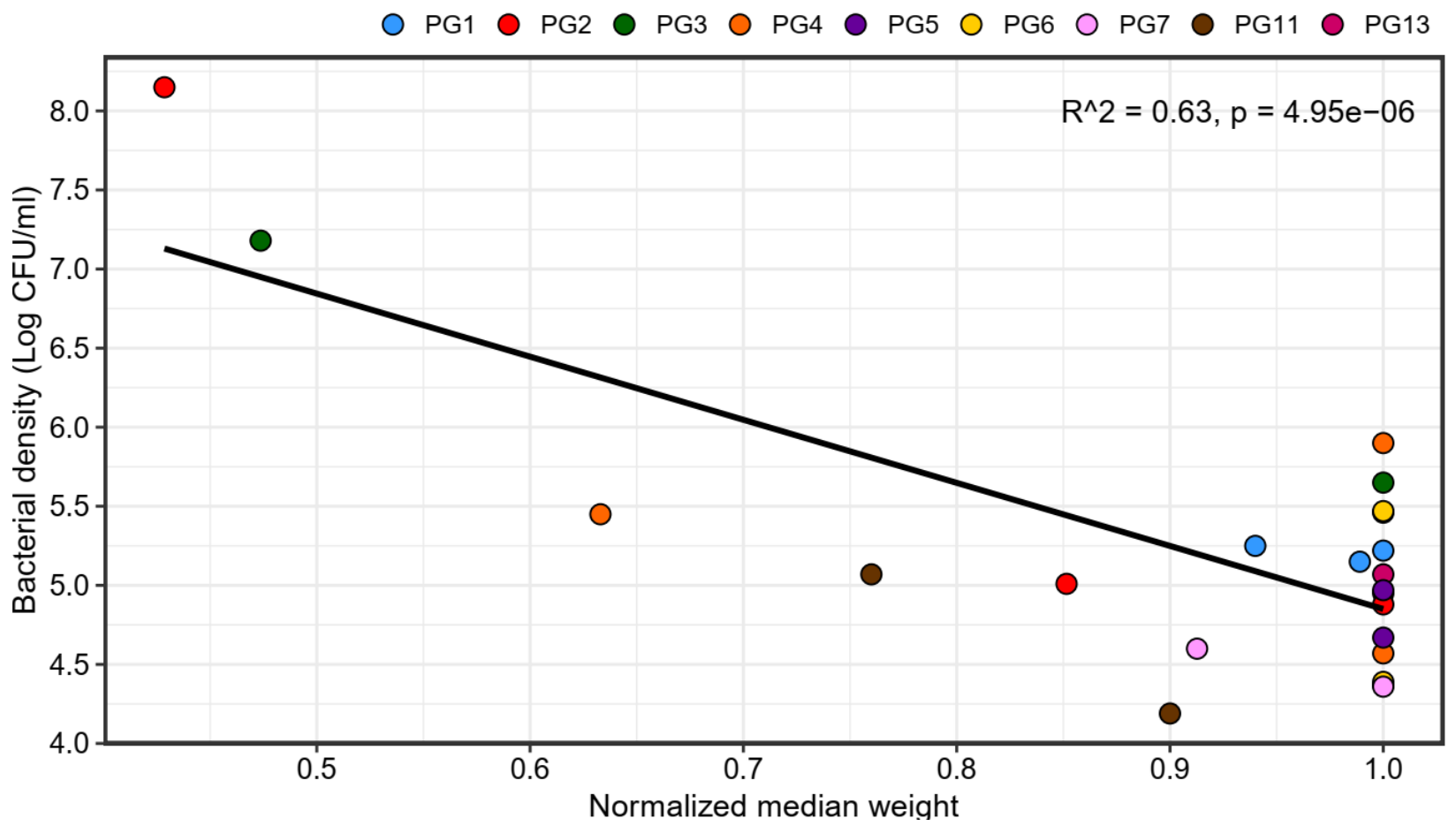




\section{Fig 2.}

662

663
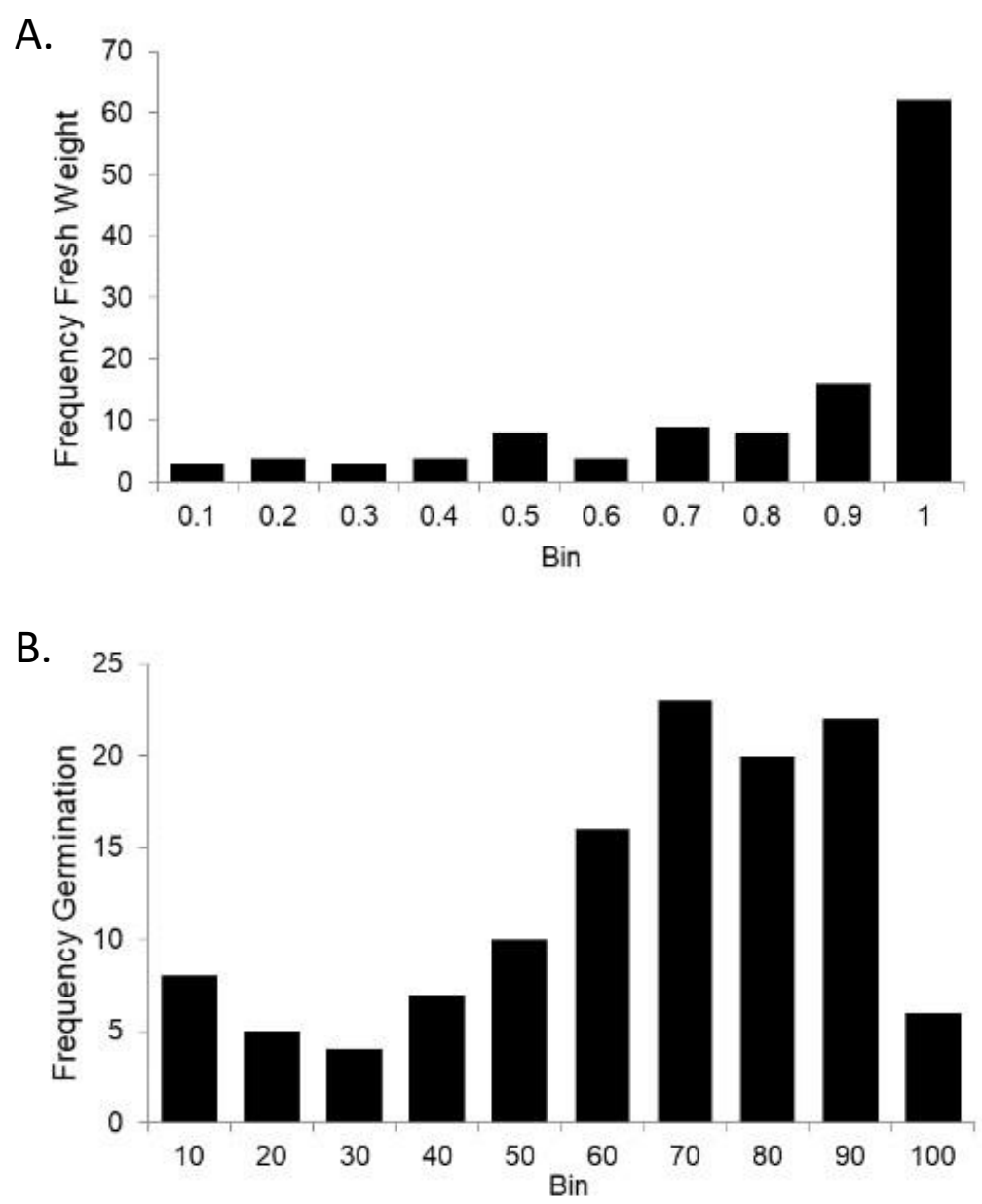

664

665

666 
bioRxiv preprint doi: https://doi.org/10.1101/2021.05.27.445966; this version posted May 28, 2021. The copyright holder for this preprint (which was not certified by peer review) is the author/funder. All rights reserved. No reuse allowed without permission.

\section{Fig 3.}

668

669

A

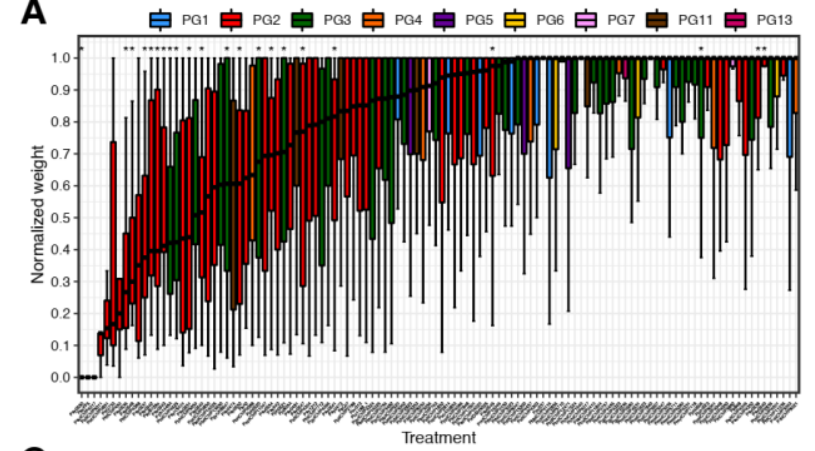

C

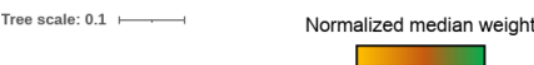

$\square$
B

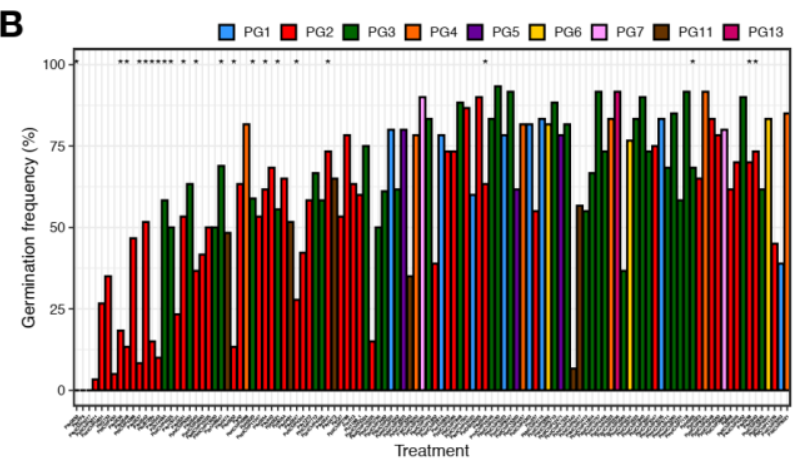

670

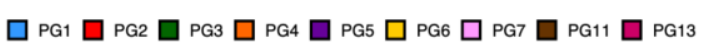

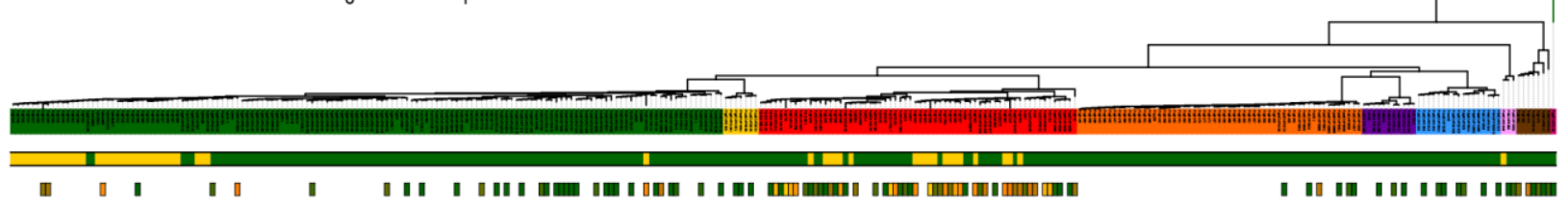


bioRxiv preprint doi: https://doi.org/10.1101/2021.05.27.445966; this version posted May 28, 2021. The copyright holder for this preprint (which was not certified by peer review) is the author/funder. All rights reserved. No reuse allowed without permission.

\section{Fig 4.}

674

675

676

A

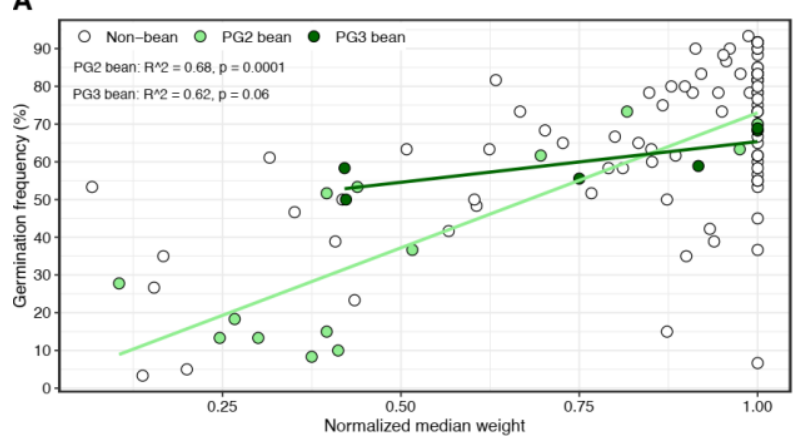

B

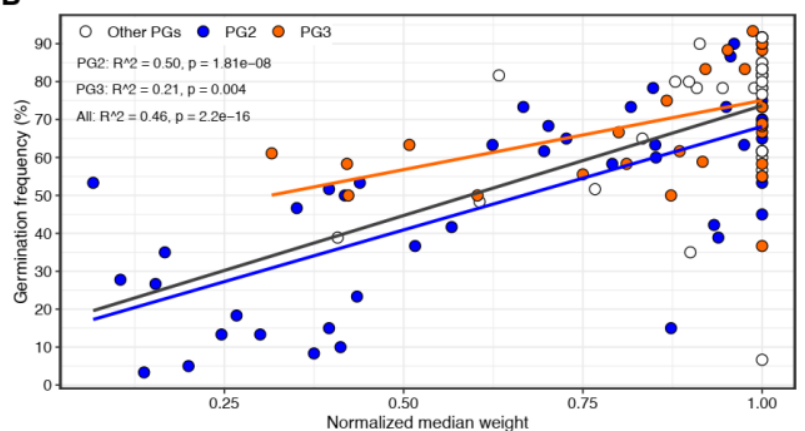


bioRxiv preprint doi: https://doi.org/10.1101/2021.05.27.445966; this version posted May 28, 2021. The copyright holder for this preprint (which was not certified by peer review) is the author/funder. All rights reserved. No reuse allowed without permission.

\section{$678 \quad$ Fig 5.}

679

680

681
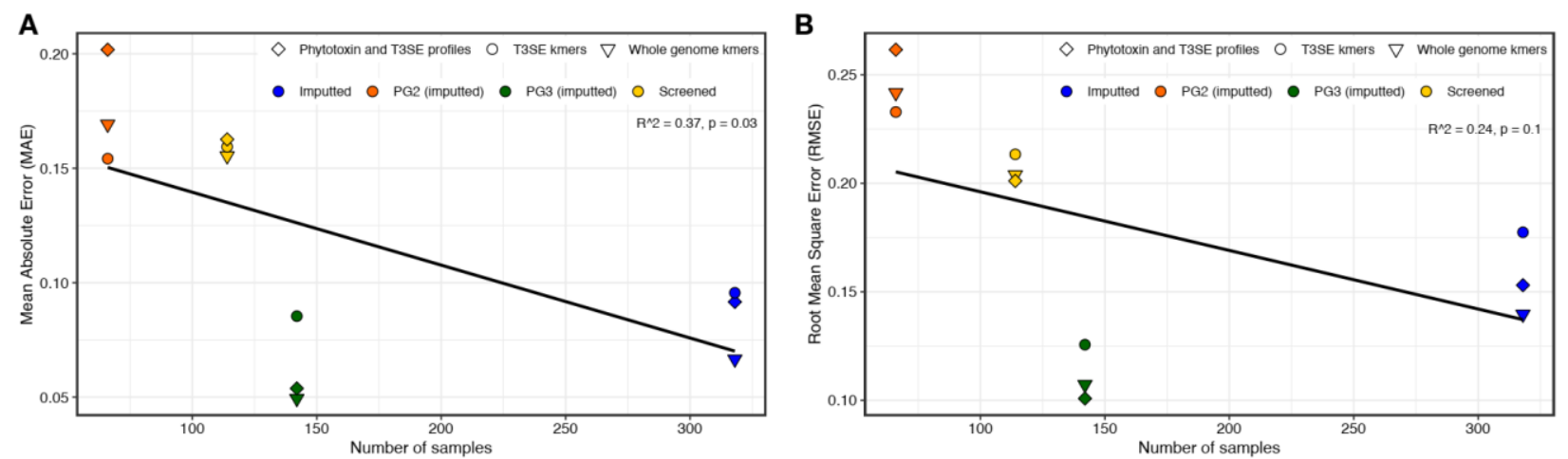

682 
bioRxiv preprint doi: https://doi.org/10.1101/2021.05.27.445966; this version posted May 28, 2021. The copyright holder for this preprint (which was not certified by peer review) is the author/funder. All rights reserved. No reuse allowed without permission.

\section{Fig 6.}

684

685

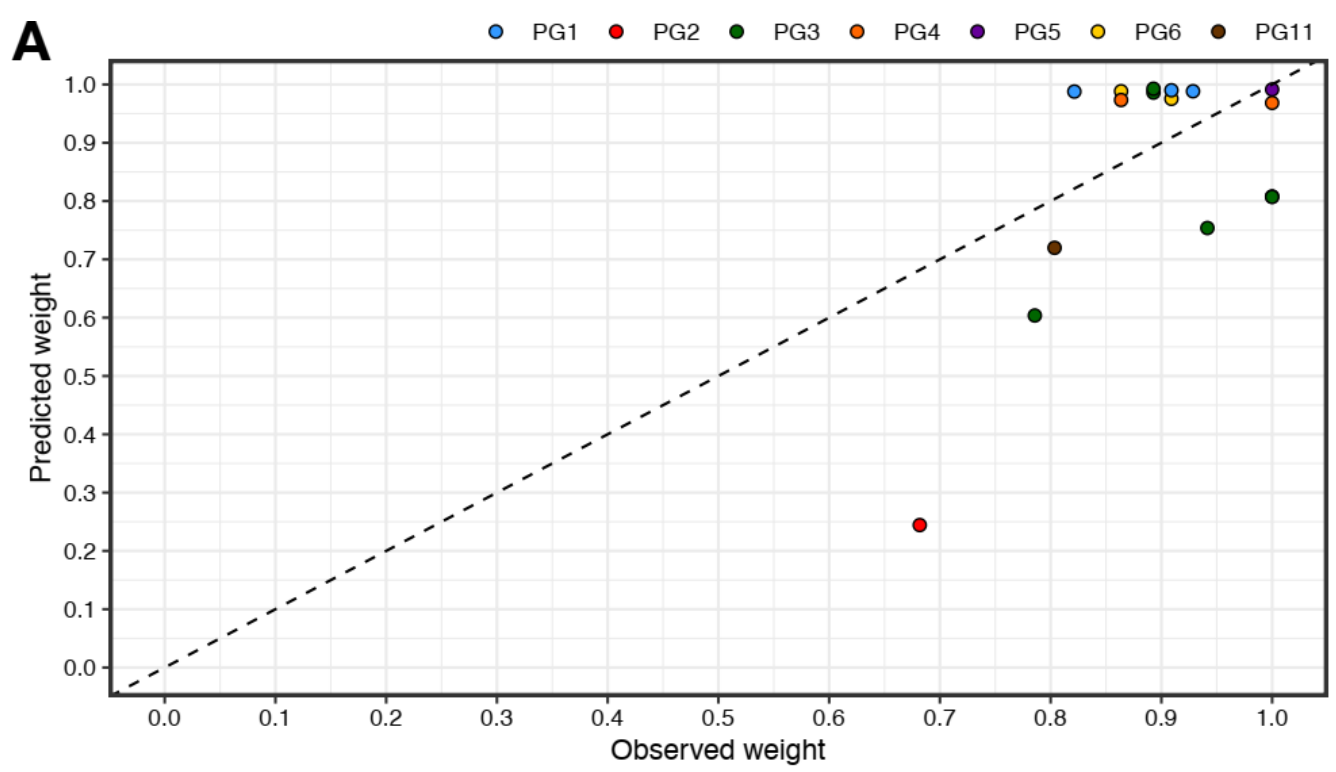

B

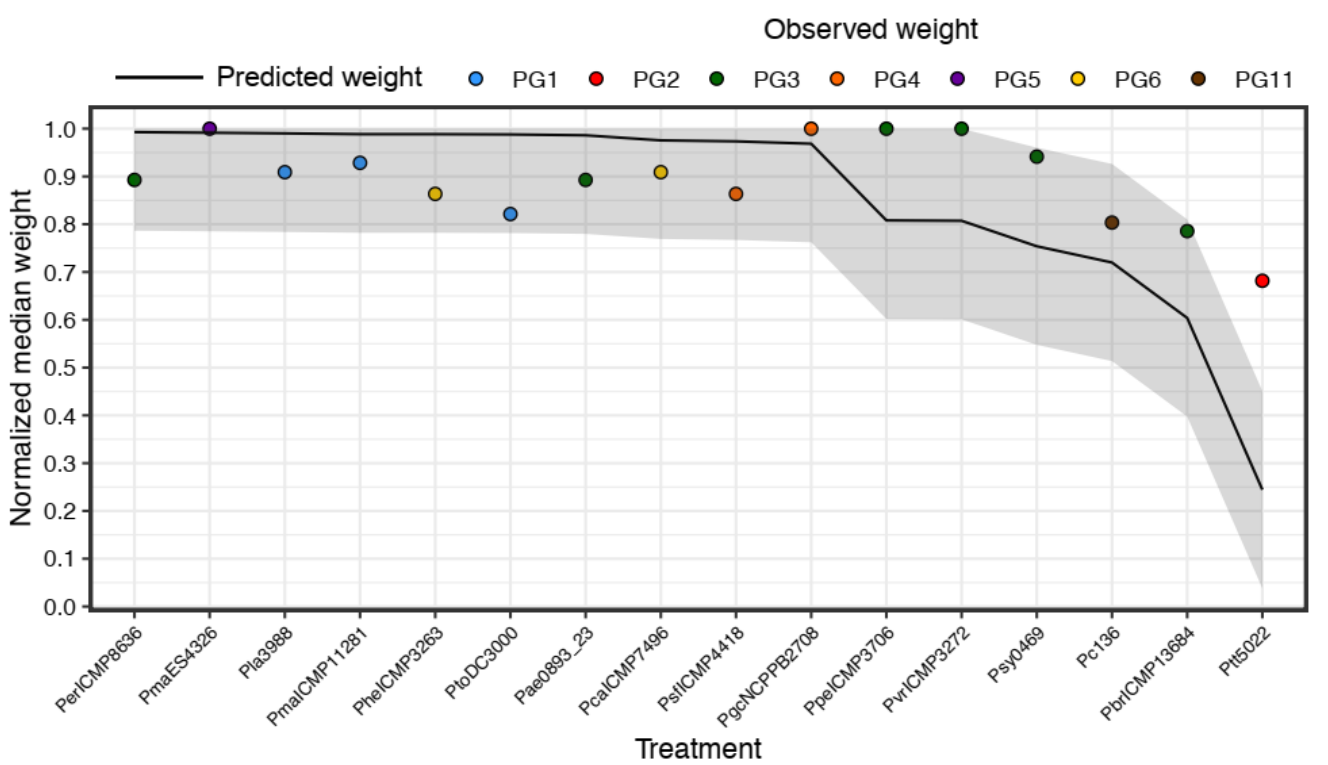

Treatment 
bioRxiv preprint doi: https://doi.org/10.1101/2021.05.27.445966; this version posted May 28, 2021. The copyright holder for this preprint (which was not certified by peer review) is the author/funder. All rights reserved. No reuse allowed without permission.

690

691
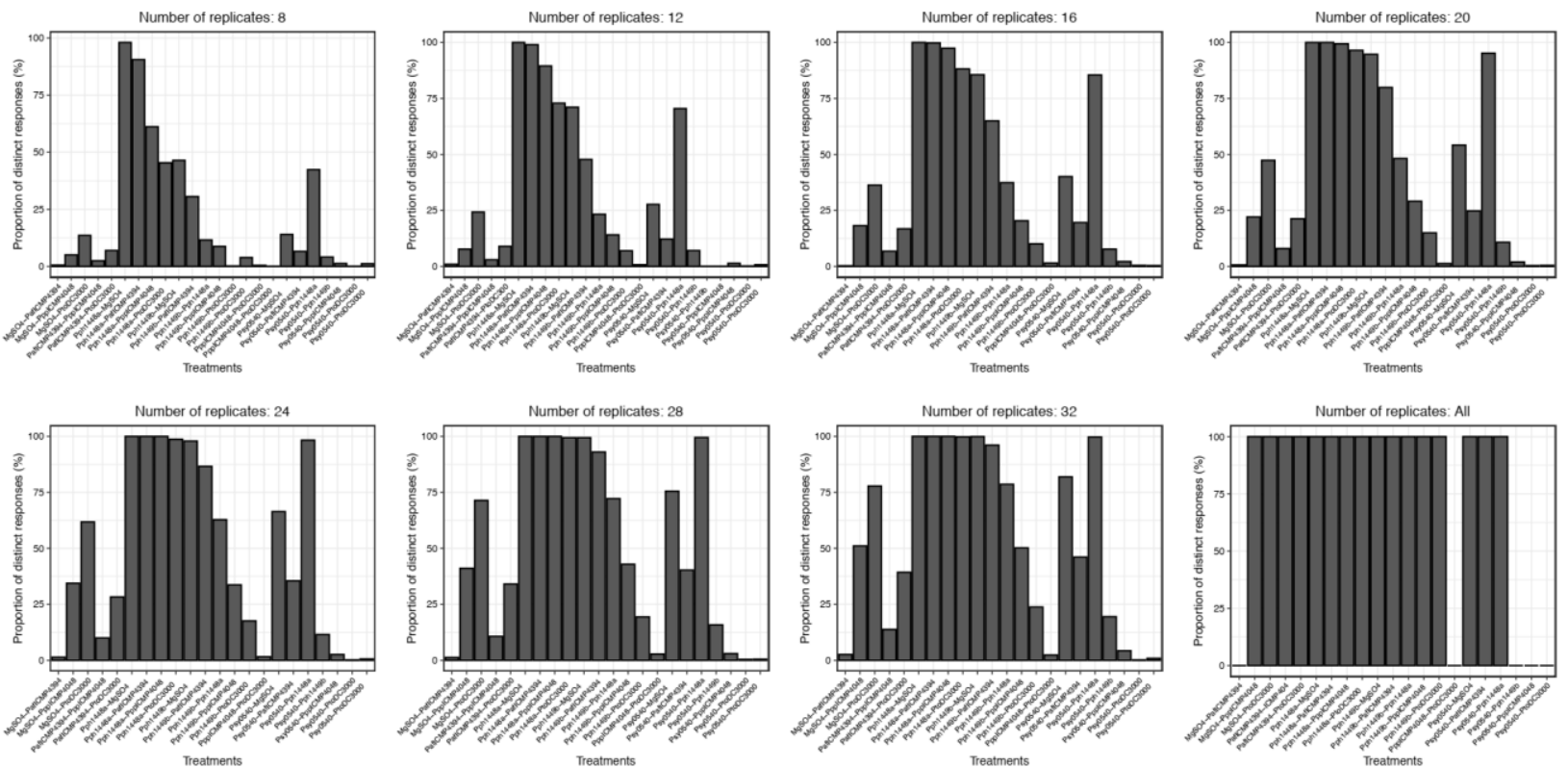

692 
bioRxiv preprint doi: https://doi.org/10.1101/2021.05.27.445966; this version posted May 28, 2021. The copyright holder for this preprint (which was not certified by peer review) is the author/funder. All rights reserved. No reuse allowed without permission.

\section{Fig S2.}

694

695

A

- NA clusters $-\mathrm{PG} 2-\mathrm{PG} 3-$ Screened

- TSSE kmers $\cdots$. Toxin T3SE binary matrix -.-. Whole genome kmers

696

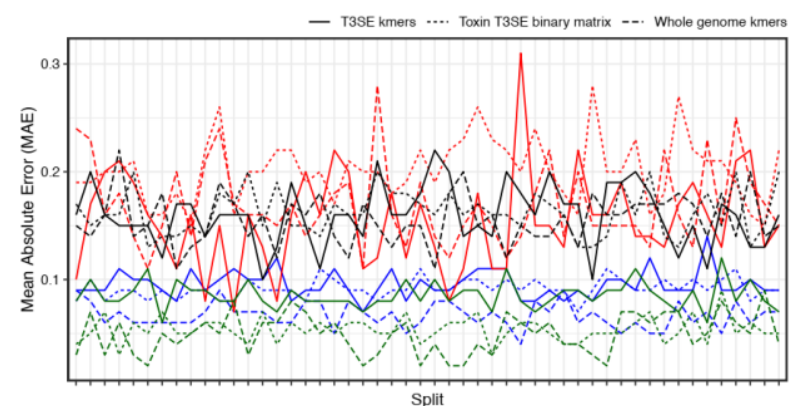

B $\quad-$ NR clusters $-\mathrm{PQ}^{\mathrm{P}}-\mathrm{PQ}^{\mathrm{P}}-$ Screened

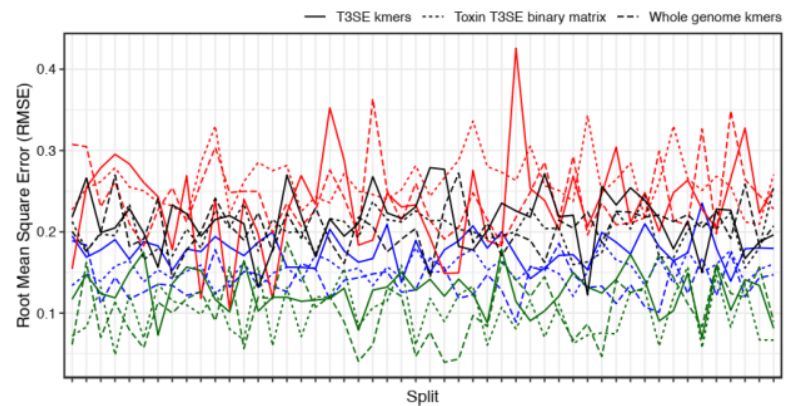

